\title{
Geografia física aplicada com o geoprocessamento nos municípios de Salinópolis e São João de Pirabas
}

O objetivo deste trabalho é expor a geografia física aplicada com o geoprocessamento nos municípios de Salinópolis e São João de Pirabas no nordeste paraense. Através de visitas as cidades, sendo norteado por aulas expositivas em reuniões e revisões bibliográficas, para a produção e elaboração de produtos cartográficos. Os principais enfoques foram sobre as caracterizações das áreas de estudo, como as posições geográficas, as rodovias de acesso, as características geológicas, geomorfológicas, da vegetação, hidrografia das localidades estudadas, as principais formas de uso e ocupação e os processos de urbanização e econômico dos municípios. Foi observado que a área de Salinópolis sofre com constante ação dinâmica, tanto na morfologia quando econômica, e está dinâmica é visivelmente diferente da dinâmica do Munícipio de São João de Pirabas, principalmente no aspecto econômico.

Palavras-chave: Mangue; Antropismo; Mapa; Geomorfológia.

\section{Physical geography applied with geoprocessing in the municipalities of Salinópolis and São João de Pirabas}

The objective of this work is to expose the physical geography applied with the geoprocessing in the municipalities of Salinópolis and São João de Pirabas in the northeast of Pará. Through visits to cities, being guided by expository classes in meetings and bibliographic reviews, for the production and elaboration of cartographic products. The main focuses were on the characterization of the study areas, such as geographic positions, access roads, geological, geomorphological, vegetation, hydrographic characteristics of the studied locations, the main forms of use and occupation and the processes of urbanization and economics of the municipalities. It was observed that the Salinópolis area suffers from constant dynamic action, both in morphology and economics, and this dynamic is visibly different from the dynamics of the Municipality of São João de Pirabas, mainly in the economic aspect.

Keywords: Mangrove; Anthropism; Map; Geomorphology.

Reviewed anonymously in the process of blind peer.

Ana Marcela Alves dos Santos

Faculdade de Tecnologia em Geoprocessamento,

Brasil

http://lattes.cnpq.br/8531787347973594

http://orcid.org/0000-0002-9498-8587 santos@hotmail.com

\section{Fabiana Cardoso Leite (iD)}

Universidade Federal do Pará, Brasil http://lattes.cnpq.br/6042133186211033

http://orcid.org/0000-0003-1877-7451

fabicardoso19ufpa@gmail.com

Larissa Losleny Pinto Fontenele (iD Universidade Federal do Pará, Brasil http://lattes.cnpq.br/2140229786778397 http://orcid.org/0000-0002-5845-5855 larissalosleny5122@gmail.com
Manoela Ferreira de Souza (D)

Universidade Federal do Pará, Brasil

http://lattes.cnpq.br/0397584594063823

http://orcid.org/0000-0003-3791-2970

manufs007@gmail.com

Mateus Trindade Barbosa

Universidade Federal Rural da Amazônia, Brasil

http://lattes.cnpq.br/3324621107113370

http://orcid.org/0000-0003-0570-5475

mateustrindade3000@gmail.com

Francimary da Silva Carneiro

Universidade Federal Rural da Amazônia, Brasil http://lattes.cnpq.br/8657235544233319

http://orcid.org/0000-0002-1693-8779

francimarycarneiro@gmail.com
Brendo Luiz Araújo Alves

Universidade do Estado do Pará, Brasil (iD

http://lattes.cnpq.br/9762723896318900 http://orcid.org/0000-0003-3306-0766

brendo_luiz96@hotmail.com
Referencing this:

SANTOS, A. M. A.; LEITE, F. C.; FONTENELE, L. L. P.; SOUZA, M. F. BARBOSA, M. T.; CARNEIRO, F. S.; ALVES, B. L. A.. Geografia física aplicada com o geoprocessamento nos municípios de Salinópolis e São João de Pirabas. Natural Resources, v.11, n.2, p.30-40, 2021. DOI: http://doi.org/10.6008/CBPC2237-9290.2021.002.0005 


\section{INTRODUÇÃO}

A região Norte do Brasil é caracterizada por plataformas continentais extremamente largas, em sua maioria recoberta por sedimentos lamosos, estes sofrem influência da descarga do Amazonas (MUEHE, 1998). Essa região abrange desde o extremo norte do estado do Amapá até o golfão Maranhense, sendo compartimentada em outros três macrocompartimentados, que são o Litoral do Amapá, delimitado entre o Cabo Orange e flanco sul do Cabo Norte; O Golfão Amazônico, que abrange a área do Cabo Norte à Ponta Taipu; e Litoral de Reentrâncias Pará-Maranhão, delimitado entre Ponta Taipu à Ponta dos Mangues Secos.

A geologia é a ciência que possui como campo de estudo a estrutura terrestre, como a forma externa e as fases da história física da Terra, um estudo dos fenômenos geológicos (GUERRA, 2008). Este dividido em grandes Éons, que correspondem aos maiores intervalos do tempo geológico, arqueano, proterozóico e Fanerozóico, estes são subdivididos em períodos menores denominados Eras. As Eras são subdivididas em períodos, e consequentemente dividido em épocas. A era cenozoica, é a mais recente ou última era, a que estamos. Antes dela vem a mesozoica, que significa a vida do meio, e paleozoica, que significa vida antiga. A era cenozoica se divide em dois períodos o período terciário e o período quaternário. O terciário se subdivide em duas épocas principais: o mioceno inferior e o plioceno.

No estado do Pará, há registro de ocorrência de terrenos dos Éons Arqueano, que afloram em municípios do sudeste paraense e Fanerozóico que afloram na ilha do Marajó e nordeste paraense (LUZ et al., 2013). A geomorfologia possui como objeto de estudo as formas de relevo, levando em conta a origem, estrutura, natureza das rochas, clima e as forças endógenas e exógenas atuantes como fatores construtores e destruidores do relevo (GUERRA, 2008).

Observando esse contexto e procurando contribuir com o conhecimento dos municípios litorâneos no nordeste paraense, objetivamos com este trabalho expor a geografia física aplicada com o geoprocessamento nos municípios de Salinópolis e São João de Pirabas.

\section{REVISÃO TEÓRICA}

\section{O município de Salinópolis}

A cidade de Salinópolis teve início no governo de André Vidal de Negreiros, ainda na época do Capitão-General dos Estados do Maranhão e Pará, a sua origem histórica ocorreu em 1656, quando Negreiros incumbiu o Capitão-Mor do Pará, Feliciano Correa, de estabelecer uma atalaia para indicar a estrada da Barra de Belém, por meio de tiros de canhão. O projeto fora implantado numa ponta saliente de terra numa ilha contígua à baia de Virianduba. Com isso, a região prosperou e, pouco depois, já estava formado o povoado denominado Salinas, por ter existido uma salina no litoral desse território, cuja exploração datou dos períodos coloniais. Em 1781, a localidade adquiriu categorias de Freguesia com o nome de Nossa Senhora do Socorro de Salinas e também de Vila, que foi extinta, em 1833. Em 1882, Salinas foi elevada a município, cuja instalação ocorreu em 1884. Obteve ainda, foros de Cidade, em 1901.

Entretanto, no ano de 1930, o município sofreu nova extinção, ficando o seu território anexado ao de Maracanã, até 1933, quando ocorreu sua emancipação político administrativa, em virtude da legislação 
federal proibir a duplicidade de nomes de cidades e vilas, em 1943, Salinas passou a chamar-se Salinópolis (IBGE, 2020).

Quanto ao caráter socioeconômico, a principal fonte de renda do município de Salinas, está relacionado ao período de veraneio, pois é um dos principais polos turísticos da região nordeste paraense, há investimentos em aluguel de residências, hotéis, restaurantes, resorts. Porém, mesmo com altos investimentos em infraestrutura turística e urbana, o município de Salinópolis não conseguiu constituir o turismo como atividade econômica consolidada, pois a preocupação em implantar infraestrutura dirige-se apenas a alguns locais específicos.

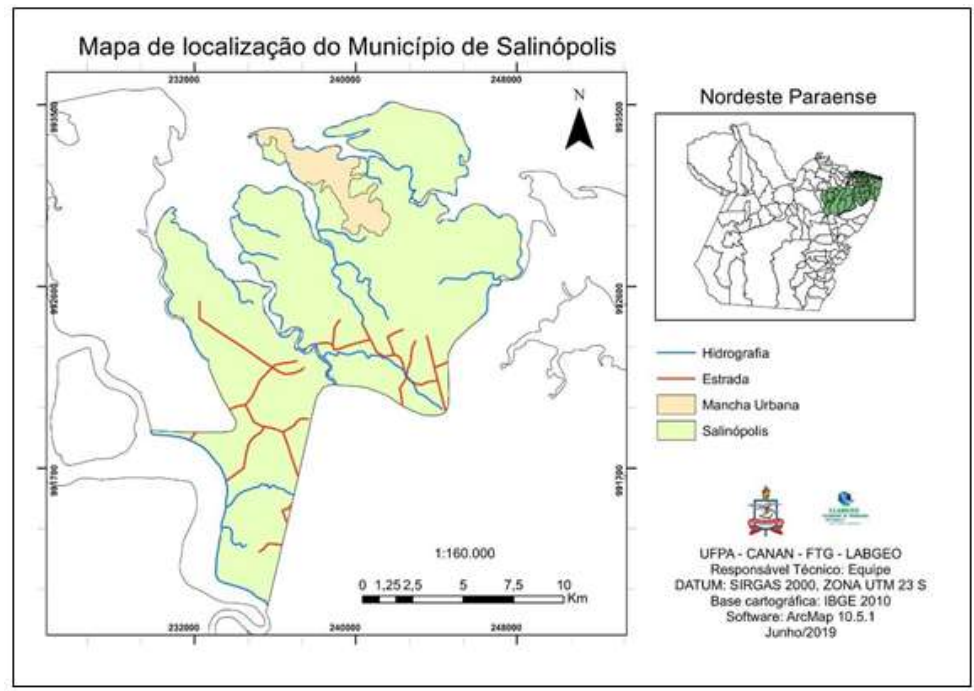

Figura 1: Mapa de localização do município de Salinópolis - PA

\section{O município de São João de Pirabas}

O município de São João de Pirabas foi criado pela lei no 5.433 de 10 de maio de 1988, estatuída pela Assembléia Legislativa do Estado do Pará e sancionada pelo Governador Hélio Mota Gueiros, sendo área desmembrada do município de Primavera, conforme o art. 1일 da referida lei. No art. 2으 estão os limites do novo município de Primavera. Santarém Novo. Salinópolis e com o Oceano Atlântico.

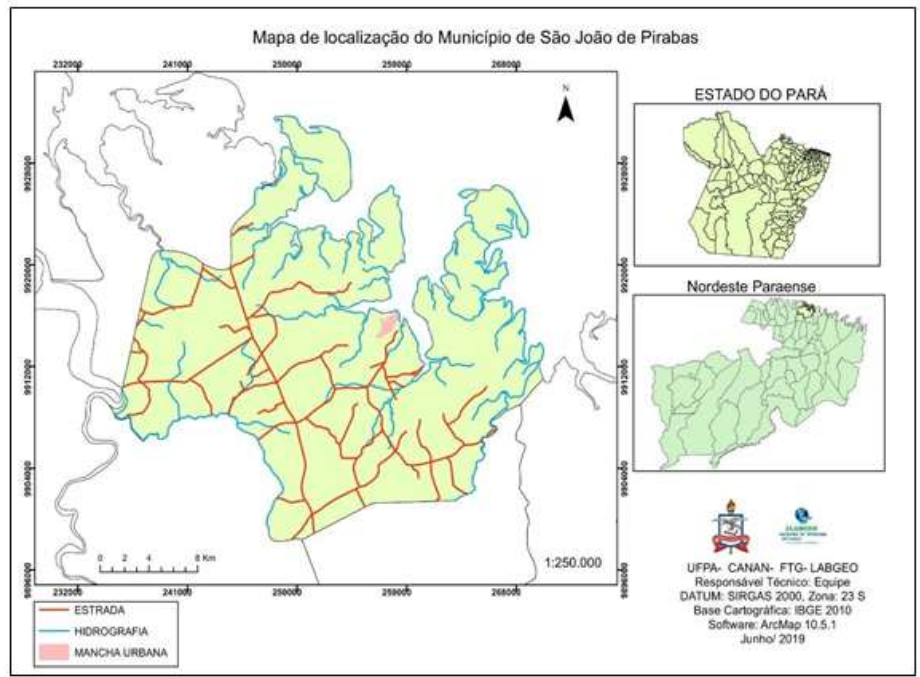

Figura 2: Mapa de localização do município de São João de Pirabas - PA. 
As principais fontes de renda do município de São João de Pirabas estão voltadas para a pesca, exportação de pescado para outros estados e pesca esportiva. Estando concentrada no extrativismo. Segundo a pesquisa realizada por Brito et al. (2015), a pesca foi a principal fonte de renda para 96,0\% dos pescadores; e cerca de 4,0\% dos aposentados em outras atividades, praticam pesca esportiva; e também há pescadores que exercem atividades secundárias de renda, como aluguel de embarcação ou comercialização de artesanato. Portanto, a renda gerada pela pesca tem sido capaz de garantir o sustento familiar dos pescadores do município. A figura 23 apresenta a sede da colônia de pescadores de São João de Pirabas.

\section{Visitas aos municípios}

A metodologia foi composta pela ida as cidades, sendo norteado por aulas expositivas em reuniões e revisões bibliográficas, para a produção e elaboração de produtos cartográficos. Os principais enfoques foram sobre as caracterizações das áreas de estudo, como as posições geográficas, as rodovias de acesso, as características geológicas, geomorfológicas, da vegetação, hidrografia das localidades estudadas, as principais formas de uso e ocupação e os processos de urbanização e econômico dos municípios.

\section{RESULTADOS E DISCUSSÕES}

\section{Mapa de unidades Geomorfológico}

A geomorfologia das ilhas de Salinópolis (figura 3 e 4) e do município de São João de Pirabas (figura 5). As macrofeições presentes nas formas litorâneas são de planície e planalto (MENDES et al., 2013). A planície correspondendo à faixa de sedimentos argilosos e arenosos, resultante das ações dos ventos, ondas e marés e apresentando o relevo plano; e o planalto correspondendo a superfície estruturada em relevo degradado, com topos levemente ondulados, perfis convexos e vertentes suaves. As áreas de Salinópolis e São João de Pirabas estão sobre uma unidade morfoestrutural de depósitos sedimentares quartenário e unidade morfoescultural de litoral de rias e mangues (LUZ et al., 2013).

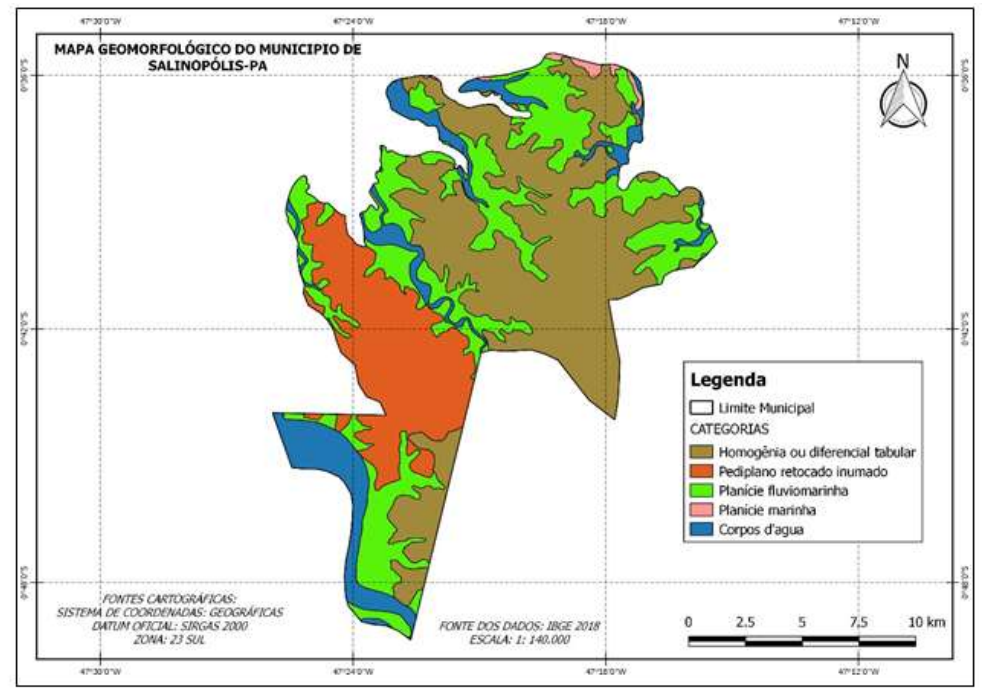

Figura 3: Mapa de unidades Geomorfológico, Salinópolis - PA. 


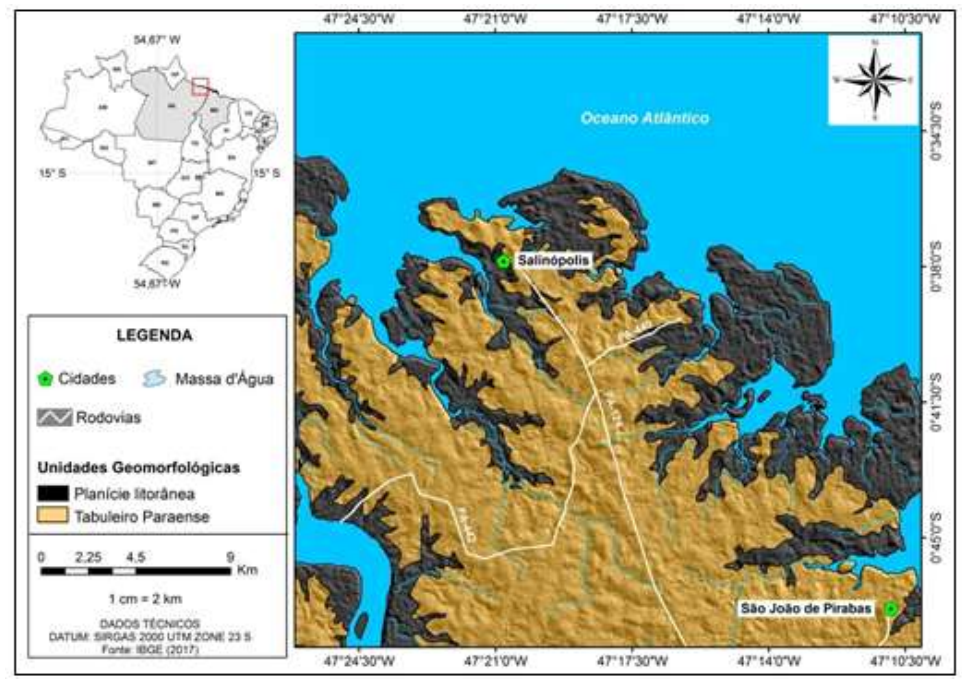

Figura 4: Mapa de Macrounidade Geomorfológicas, Salinópolis - PA.

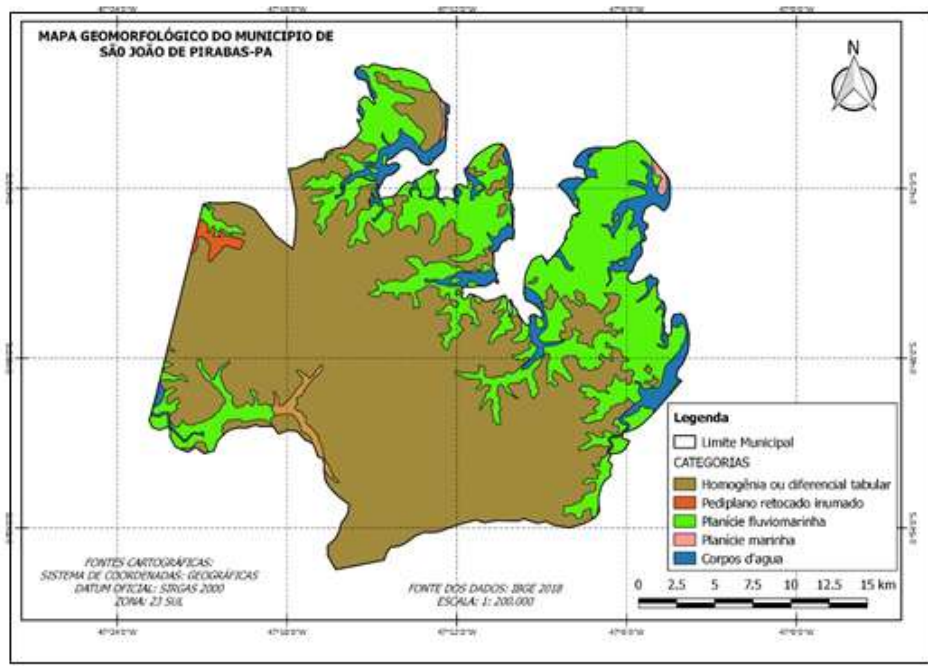

Figura 5: Mapa de unidades Geomorfológico, São João de Pirabas - PA.

\section{Vegetação}

Em Salinópolis, podemos observar a urbanização estar se expandindo para as regiões de mangue, principalmente próximo aos mangues da praia da Curvina (figura 6). Segundo Muehe (1998), o mapa de recobrimento vegetal mostra que a faixa de reentrância é predominantemente coberta pela vegetação de mangue. Estas formam um cinturão de até $30 \mathrm{~km}$ de largura e em rios com grande extensão penetram por dezenas de quilômetros para o interior do continente, esta faixa de áreas de manguezais representante de $53 \%$ da área total de manguezais.

O trabalho iniciou na Fonte do Caranã em Salinópolis (figura 7a e 7b), onde houve as primeiras explanações do trabalho de campo e da região costeira de salinas. Nesse local há presença de árvores de buriti (figura 7c), ela é um indicativo que este terreno é alagado, formando as chamadas veredas (caminhos de água). O local dessa fonte é uma exceção, pois muitas áreas de buritizais foram destruídas pela urbanização. 


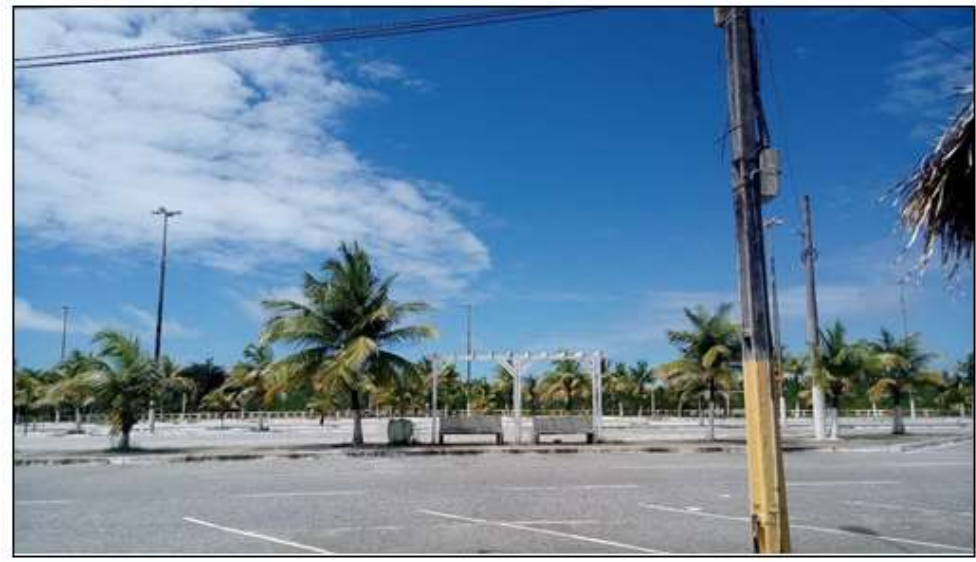

Figura 6: Urbanização próximo ao mangue da praia da Curvina, Salinópolis - PA
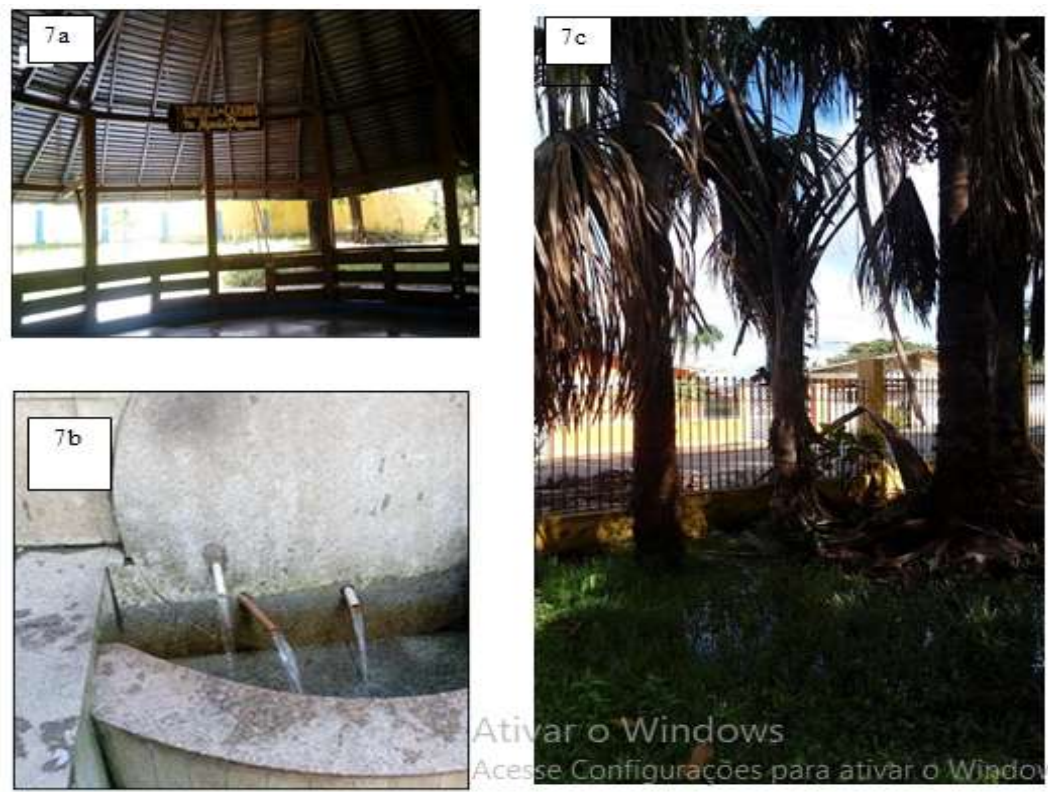

Figura 7: a) coreto "Barraca de carimbo Tia Maria", Salinopolis - PA; b) Fonte de água, Salinopolis - PA; c) Árvore de buruti - indicador de area alagada, Salinopolis - PA.

O manguezal possui árvores de Avicennia schaueriana chamada popularmente de mangue siriúba, sua função é proteger o litoral, pois a água do mar bate nos manguezais e os atravessa, quebrando a força das ondas. Isso ocorre porque a arvore possui uma estrutura aerodinâmica, com raízes, chamados de pneumatóforos, que tem o crescimento positivo, no sentindo vertical, para suportar os impactos das ondas, além de servir para respiração, colaborando com a respiração pela folha (figura 8).

Dentro dessa faixa de litoral norte do Brasil é onde se encontram as amostras mais significativas dos manguezais. Os mesmos são berçários marinhos e são extremamente impactados pela carcinicultura, fazendas de camarão dentro dos manguezais. No litoral nordestino comum e já está sendo utilizado no litoral paraense.

Na orla da cidade de Salinópolis (figura 9), há uma antiga praça, em que é possível visualizar a ação erosiva. Esta praça está sobre uma falésia, que está deixando de ser inativa e ficando ativa novamente, ou seja, está se reiniciando o processo erosivo. Este ponto fica em frente a câmara municipal de Salinópolis. Em frente a falésia, há um canal de maré denominado "canal do Sampaio", ele contorna a ilha do atalaia. 


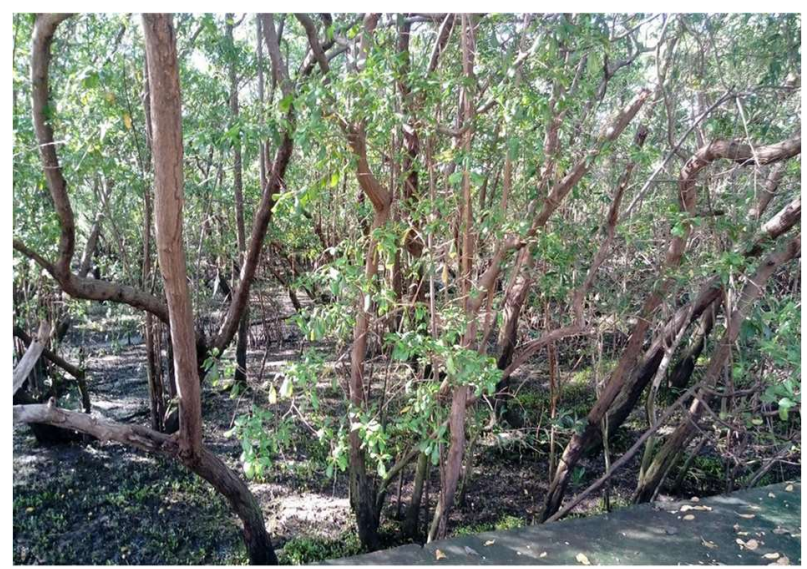

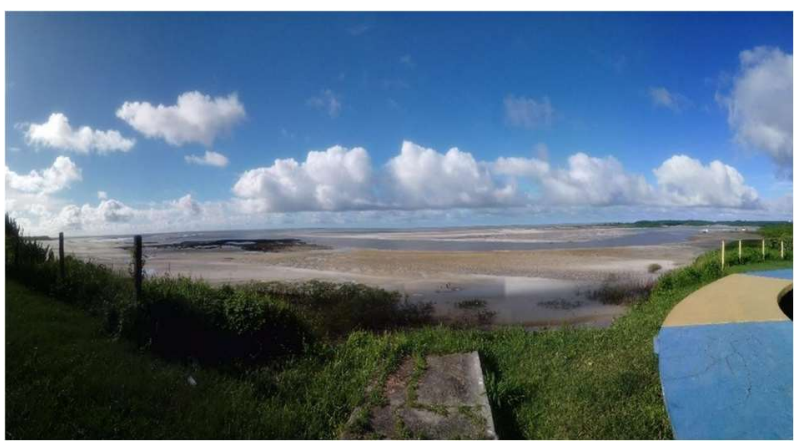

Figura 9: Praça da antiga orla de Salinópolis-PA

Figura 8: Vegetação de mangue próximo à área urbanizada, Salinópolis - PA.

Podemos observar que, na barra arenosa há fragmentos de arenito ferruginoso, sendo um indicativo de onde estava a parte da antiga orla, denominado promontório, ele é produto da ação tectônica. Então ao longo do tempo geológico houve muito recuo e não se tem uma garantia de que ele irá cessar, certamente pode continuar, pois é cíclico e vai devagar. Entre dois promontórios (figura 10) forma-se uma enseada (GUERRA, 2018). Essa enseada atualmente está com sedimentos lamosos e sendo colonizada pela vegetação de mangue.

Contudo como o processo erosivo já se iniciou, ou seja, as ondas já estão erodindo a base da falésia, o sedimento que é depositado não é o que estava em suspensão na água. Por exemplo, caso a onda não tivesse arrebentando na base da falésia, o sedimento seria mais fino, sedimento dissolvido, então ele sofreria o processo de decantação. Então a corrente de maré, vai depositar um sedimento mais fino, geralmente a argila, que vai formar o substrato lamoso, sobre o qual se estabelece a vegetação de mangue.

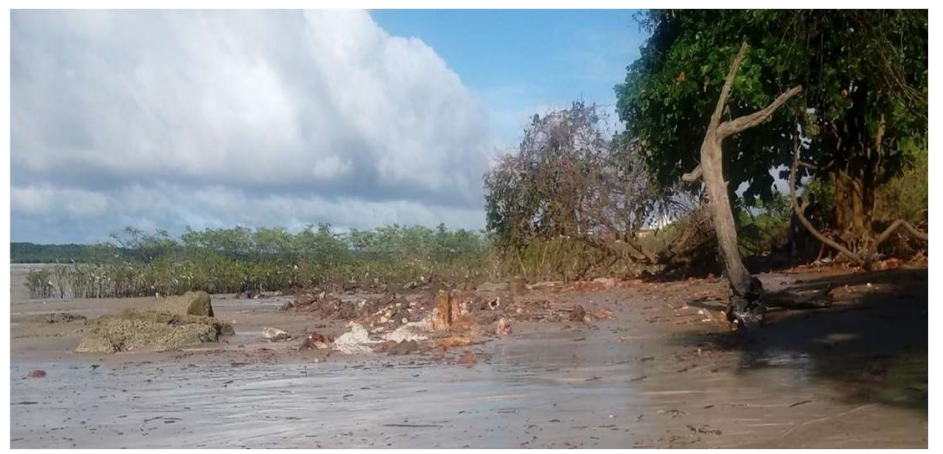

Figura 10: Barra arenosa com indicadores de erosão, Salinópolis - PA.

Porém, quando a onda alcança as partes próximas do litoral e a altura da onda fica em média superior ao dobro da profundidade, esse momento a onda arrebenta na chamada de zona de surf - zona de arrebentação. Nesse momento, ela adquiriu a capacidade de mobilizar os sedimentos do fundo oceânico e ela começa a transportá-los. Quando a onda arrebenta, há um avanço sobre o continente e a onda sofre uma reação, a chamada corrente de retorno. Como uma onda está quebrando uma sobre a outra e elas não estão na mesma frequência, então a tendência é a saída pela tangente, gerando outra corrente. Logo, se a onda começa arrebentar mais próximo do continente, e devido ela der mais energia, irá transportar um sedimento de maior granulometria. Consequentemente, vai contribuir para a formação do banco arenoso 
(praia), sobre os pneumatóforos e os manguezais vão morrer.

Em seguida, descemos para as barras arenosas, esses municípios estão localizados no litoral de reentrâncias do nordeste paraense, tendo unidades litoestratigráficas de idade cenozoica. Nessa região, são caracterizadas por duas formações geológicas, sendo a formação Pirabas que se encontra na base, composta por calcário na praia do Atalaia, sendo rica em fosseis. É originaria do fundo de oceano, no período que o mar estava mais alto e a plataforma continental estava para o interior (figura 11). E formação Barreiras ou formação continental. Os sedimentos pós-barreiras é um conjunto sedimentos mais jovens, ainda em processos recentes de litificação.

No momento em que o rio está escoando ou quando a maré sobe, é possível notar que, em alguns lugares, formam-se pequenas barras ou pequenos bancos lamosos, ainda não estabilizados pela vegetação, chamados aluviões holocênicos, ou seja, sedimentos que tem no máximo de 10 a 12 mil anos de idade. A formação Pirabas é da época do mioceno, em torno de 28 milhões de anos. 0 grupo barreiras é do plioceno, final do terciário e se estende pelo quaternário até a época do pleistoceno. No pleistoceno, há transição entre os grupos barreiras e o pós-barreiras. E no holoceno tem uma discordância, marcada pela linha de pedra (stone line), mostrando a divisão dos sedimentos pós-barreira e a formação barreira, esta linha de pedra é visível na falésia se a mesma não estiver vegetada.

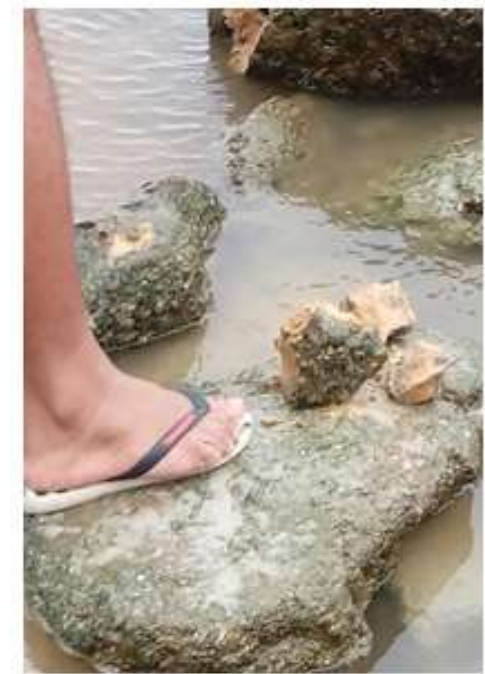

Figura 11: Formação Pirabas, composta por calcário na praia do Atalaia, Salinópolis - PA

Os sedimentos pós-barreira são sedimentos mais recentes do início do quaternário, 2 milhões de anos, o período do quaternário se subdivide em pleistoceno e o holoceno. Os manguezais e as praias estão enquadrados nos sedimentos holocênicos, sedimentos mais jovens, que não foram totalmente estabilizados.

Na praia do Atalaia, chegamos no momento da maré alta (figura 12). A maré alcançar pré-a-mar em um período de 7 minutos, denominado de estofo da maré, ficando praticamente parada por 7 minutos e, após esse momento, há a troca de fluxo. Após esse momento, a maré recua por 6 horas até alcançar a baixa mar. 


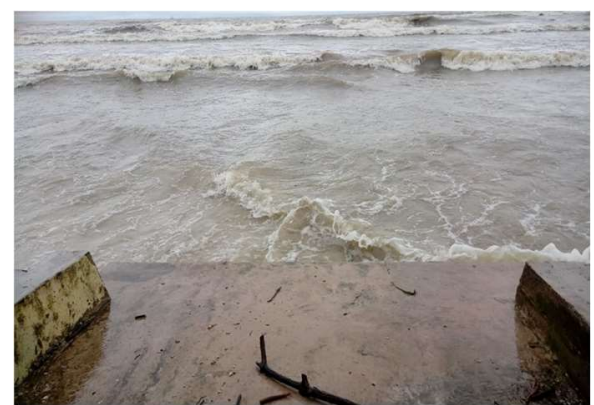

Figura 12: Maré alta na praia do Atalaia, Salinópolis - PA.

O processo da maré acontece pelo deslocamento vertical da água, é o intumescimento, a face da Terra que tiver voltada para a lua vai sofrer o intumescimento, o escoamento horizontal da água na direção do continente (maré). O processo do regime de ondas é atmosférico, sendo a transferência da energia do vendo para a superfície da água, que gera as ondas. Então as marés são processos astronômico (relacionado a gravitação - a atração que a lua e o sol também, estão exercendo sobre a Terra) e as ondas são processos atmosférico.

Nesta área da praia, foi possível observar dois padrões de organização e ocupação do espaço. Para a esquerda nós temos o setor das residências, localizada sobre um planalto e na borda da falésia, esta estar toda descaracterizada e apresenta-se como uma feição muito erosiva (figura 13). Para o lado direito, há outro padrão de ocupação, que são as barracas e outo tipo de feição que são as dunas. Atrás das barracas há um acumulo de matéria orgânica, descartado de forma irregular e os efluentes (esgoto que é lançado). Estes efluentes alteram o padrão da vegetação.

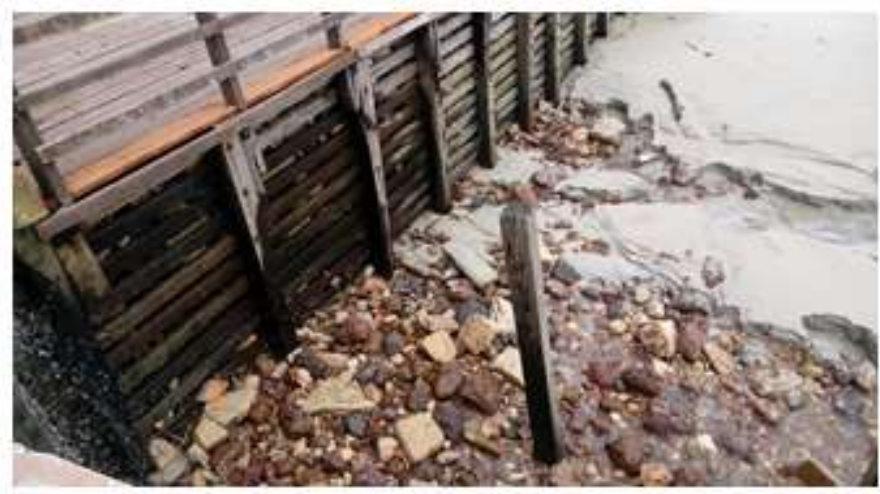

Figura 13: Falésia urbanizada, Salinópolis - PA.

As dunas se formam pelo seguinte processo, primeiro o sedimento é depositado na praia pela ação das ondas. Em seguida, devido os sedimentos estar expostos a radiação, ocorre a evaporação, nesse momento os mais finos são transportados pelos ventos e formam os grandes campos de dunas, depois que a duna começa a ser formada vem a vegetação pioneira, em tempo muito curto ela começa a se fixar na duna (essa vegetação é um ecossistema adaptado a um solo arenoso, salino e com muita radiação). Essa vegetação devido ser pioneira tem o ciclo muito curto, mas ela prepara o terreno para uma formação vegetal mais exigente e duradora (figura 16). Esse processo é muito evidente na praia do Atalaia, onde há o extrato herbáceo e o extrato arbustivo (figura 17).

A vegetação características das dunas é a vegetação de restinga, com espécies características das 
dunas, como o muruci e o ajuru. A aningá aparece na água onde há o afloramento de água (nos lagos interdunares), então ela se comporta quase como uma vegetação exógena e é consequência da água doce que chega com nível muito grande de matéria orgânica. As dunas foram eruditas agora no mês março, devido aos altos níveis de pluviosidade nesse período.

No campo de dunas da ilha da atalaia, observamos a feição de solta -vento, que é totalmente distinta do barlavento tanto no poste da vegetação e na tipologia da vegetação da unidade. Na feição do solta -vento, a vegetação consegue se estabelecer e formar o primeiro horizonte, o horizonte 0 , que é mais superficial e orgânico, que vai fornecer os nutrientes para uma vegetação mais exigente.

A praia e a duna estão em um nível topográfico mais elevado, o manguezal está em um nível topográfico mais baixo. A água entra pela corrente de maré, nesse processo ele sedimenta, nesse momento o material sedimentar que estava em suspensão sofre o processo de decantação. Esse material é a argila, um material que fica dissolvido, quando reduz a movimentação, o sedimento começa a decantar então vai formando o solo lamoso sobre o qual se estabelece a vegetação de mangue aqui tem mais energia, é uma ação da onda e do vento então consequentemente aumentar a granulometria (figura 14).

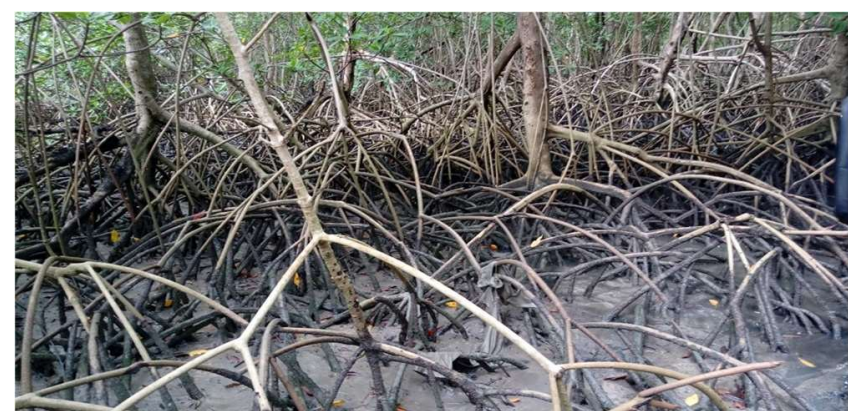

Figura 14: Manguezal, Salinópolis - PA.

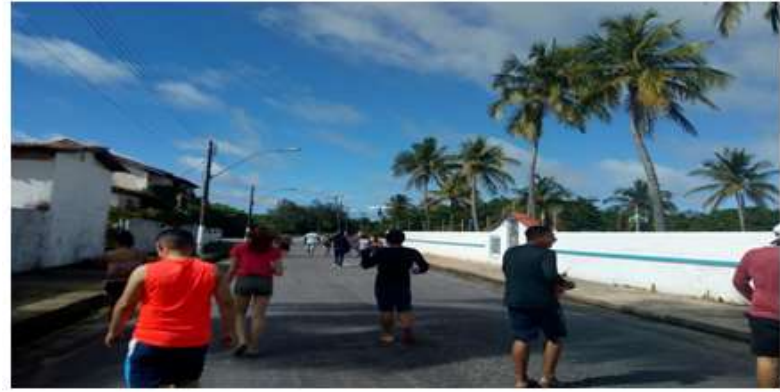

Figura 15: Crescimento da Urbanização para as áreas de mangue, Salinópolis - PA.

Foi observado um aumento do processo de urbanização no manguezal, que acaba gerando a poluição, principalmente porque não há coleta e tratamento de esgoto e consequentemente ocorre o lançamento de efluente para o mangue. Além de que no monitoramento que o INPE faz, através do programa PRODES, nota-se que entrara o corte de madeira nessa região, e não tem mais madeira para serraria, então eles estão cortando as madeiras das árvores dos manguezais (siruibeiras). Construção de habitações tem impacto muito pequeno, porque os caboclos mesmo fazem esse tipo de atividade. 0 curral também tem impacto muito pequeno.

Em Salinopolis o que mais impacta é a urbanização sobre essas áreas de manguezais (figura 15). Principalmente, devido a grande quantidade de loteamento na ilha do Atalaia. Nisso, observamos a grande exploração dos manguezais tanto com a questão da urbanização, quanto a questão da carcinicultura.

As principais fontes de renda do município de São João de Pirabas estão voltadas para a pesca, exportação de pescado para outros estados e pesca esportiva. Estando concentrada no extrativismo. Segundo a pesquisa realizada por Brito et al. (2015), a pesca foi a principal fonte de renda para 96,0\% dos pescadores; e cerca de 4,0\% dos aposentados em outras atividades, praticam pesca esportiva; e também há pescadores que exercem atividades secundárias de renda, como aluguel de embarcação ou comercialização 
de artesanato. Portanto, a renda gerada pela pesca tem sido capaz de garantir o sustento familiar dos pescadores do município. A figura 16 apresenta a sede da colônia de pescadores de São João de Pirabas.

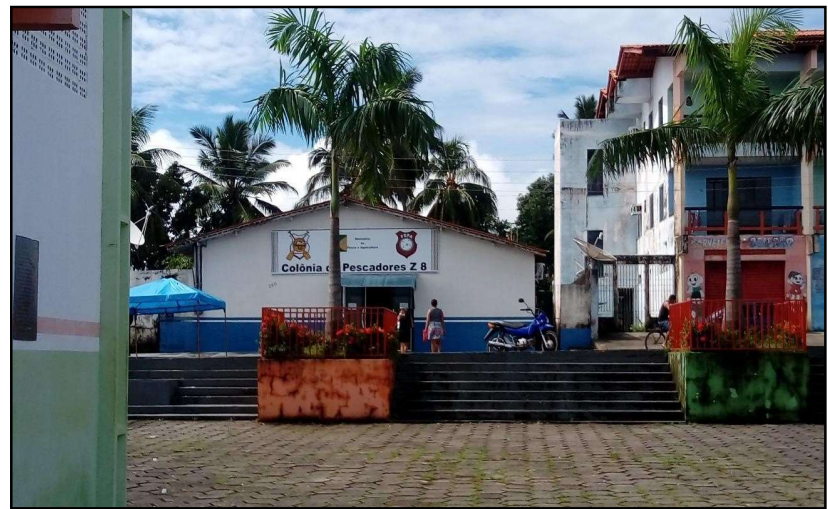

Figura 16: Sede da Colônia de Pescadores de São João de Pirabas - PA

\section{CONCLUSÕES}

Levando em consideração os aspectos observados, podemos perceber as diferenças físicas, sociais e econômicas dos municípios estudados. Assim concluímos que a área de Salinópolis sofre com constante ação dinâmica, tanto na morfologia quando econômica, e está dinâmica é visivelmente diferente da dinâmica do Munícipio de São João de Pirabas, principalmente no aspecto econômico.

\section{REFERÊNCIAS}

BRITO, F. M. O.. Salinópolis-PA: organização Sócio-Espacial de um Lugar Atlântico Amazônic. Dissertação (Mestrado em Geografia) -Universidade Federal de Santa Catarina Florianópolis, 2004.

BRITO, T. P.; OLIVEIRA, A. N. D.; SILVA, D. A. C.; ROCHA, J. A. S.. Caracterização socioeconômica e tecnológica da atividade de pesca desenvolvida em São João de Pirabas - Pará Brasil. Ambiência: Revista do Setor de Ciências Agrárias e Ambientais, v.11, n.3, 2015

PROST, M. T.; MENDES, A. C.. Ecossistemas amazônicos: dinâmicas, impactos e valorização dos recursos naturais. Belém: Museu Paraense Emílio Goeldi, p.157-187, 2011.

FRANÇA, C. F.; SOUZA FILHO, P. W. M.. Análise das mudanças morfológicas costeiras de médio período na margem leste da Ilha de Marajó (PA) em imagem Landsat. Revista Brasileira de Geociências, v.33, n.2, p.127-136, 2003.

FRANÇA, C. F.. Morfologia e mudanças costeiras da margem leste da llha de Marajó (PA). Tese (Doutorado em Geologia) - Universidade Federal do Pará, Belém, 2003.

LUZ, L. M.; RODRIGUES, J. E. C.; PONTE, F. C.; SILVA, C. N. Atlas Geográfico Escolar do Estado do Pará. Belém: GAPTA/UFPA, 2013.

GREGÓRIO, A. M. S.; MENDES, A. C.; BUSMAN, D. V.. Erosão na praia do Atalaia: Salinópolis/PA. In: MENDES, A. C.; PROST,
M. T.; CASTRO, E.. Ecossistemas amazônicos: dinâmicas, impactos e valorização dos recursos naturais. Belém: MPEG, 2011.

GUERRA, A. T.. Novo dicionário geológico-geomorfológico. 6 ed. Rio de Janeiro: Bertrand Brasil, 2008.

IBGE. Histórico de Cidades, Salinópolis-PA. IBGE, 2020.

LEITE, W. S.. Estratigrafia de Dunas Costeiras de SalinópolisPA em associação com variações pluviométricas. Bragança, 2010.

MARINHO, R. S.. Faces da expansão urbana em Salinópolis, zona costeira do Estado do Pará. Dissertação (Mestrado em Geografia) - Universidade Federal do Pará, Belém, 2009.

MENDES, A. C.; SILVA, M. S.; SANTOS, V. F.. Análise do meio físico para gestão ambiental das ilhas de Algodoal e Atalaia (NE do Pará). In: PROST, M. T.; MENDES, A. C.. Ecossistemas costeiros: impactos e gestão ambiental. 2 ed. Belém: Museu Paraense Emílio Goeldi, p.103-111, 2013.

MUEHE, D.. O litoral brasileiro e sua compartimentação. In: CUNHA S. B.; GUERRA, A. J. T.. Geomorfologia do Brasil. 9 ed. Rio de Janeiro: Bertrand Brasil, 1998.

SOUZA, G. B. N.. Uso do Solo da Ilha da Atalaia no município de Salinópolis (PA): desafios para o reordenamento territorial. Belém: Universidade Federal do Pará, 2012.

A CBPC - Companhia Brasileira de Produção Científica (CNPJ: 11.221.422/0001-03) detém os direitos materiais desta publicação. Os direitos referem-se à publicação do trabalho em qualquer parte do mundo, incluindo os direitos às renovações, expansões e disseminações da contribuição, bem como outros direitos subsidiários. Todos os trabalhos publicados eletronicamente poderão posteriormente ser publicados em coletâneas impressas sob coordenação da Sustenere Publishing, da Companhia Brasileira de Produção Científica e seus parceiros autorizados. Os (as) autores (as) preservam os direitos autorais, mas não têm permissão para a publicação da contribuição em outro meio, impresso ou digital, em português ou em tradução. 